\title{
Teachers Are Not Always Right: Links between Teacher Ratings and Students' Creativity Scores, Self-Images and Self-Ratings in School Subjects
}

\author{
Eva V. Hoff* and Ingegerd Carlsson
}

Department of Psychology, Lund University, Lund, Sweden

\begin{abstract}
The study investigated the relation between teachers' assessments and creativity tests. Earlier research has shown that teachers are not accurate judges of creativity. We sought to clarify what might bias teachers' assessments. Results from creativity tests were compared with school children's self-descriptions and teachers' ratings of creativity. Sixty-one 10-year old children (31 girls, 30 boys) took three creativity tests (e. g. Alternate Uses Test) and filled out a self-image inventory. Their teachers $(\mathrm{N}=7)$ filled out a 16 -item scale for each student. The results showed that high levels of students' academic achievement, cooperation ability and psychological well-being were associated with the teachers' assessments of their students' creativity but not with the creativity measures. The teacher assessments of creativity were significantly related to only one of three creativity measures. Moreover, teachers rated both traits typical of creative people and traits typical of non-creative people as closely linked to their conception of creativity. The teacher ratings of creativity were not related to the children's idea generating ability.
\end{abstract}

Keywords: Creativity, school, teachers' ratings, self-ratings, creativity tests, self-image.

\section{INTRODUCTION}

One important task for schools is to encourage and develop children's creativity. To be able to foster creativity in children it is important that educators have a clear idea about what creativity is and how it is manifested. This task of defining and recognizing creativity, however, is not an easy one. Most creativity researchers agree that an operational definition of creativity must include the making of a product that is both novel and appropriate [1]. We also assume that creativity is a productive or generative, novel way of experiencing reality, including individuals' own selves $[2,3]$.

However, there are many reasons why these definitions might not be enough to help teachers to recognize creativity in their students. One anecdote should help illustrate the problem. Some years ago, while the first author was working as a substitute teacher in an elementary school, she was asked to teach an art class. The task she gave the children was to represent spring in an artistic design. The children were given a certain amount of choice about what to do and how to do it. However, most of them opted simply to incorporate green leaves into their designs. Having 25 children to supervise, the teacher could not check on the progress of every student or encourage them to experiment with a variety of ideas. In the end, only one child moved past the green leaf motif to produce an original representation of spring. He did not paint green on the cardboard like the others; he painted his whole face green with pastel crayons. This idea was, without a doubt, novel and perhaps even appropriate. If some professional artists are recognized for

*Address correspondence to this author at the Lund University, Department of Psychology, Box 213, SE-221 00 Lund, Sweden; Tel: +46 46 2228767; Fax: +46 462224209; E-mail: eva.hoff@psychology.lu.se their body paintings, why shouldn't a child also express creativity in this way? Nevertheless, this novel approach to the art assignment was not appreciated by the surprised and somewhat frazzled teacher with 25 students in her care. Luckily for the teacher, the other 24 children were wellbehaved (conforming) students and sat quietly while she spent a good quarter of an hour scrubbing the face of the one child who had dared to try something different. This child's representation of spring could well be judged to be a novel way of experiencing reality including the child's self. According to our definition of creativity presented above, he succeeded in producing a creative product. However, this creativity would probably be lost on many teachers. Instead, they would find his behavior annoying and maybe even view it as misconduct. The intention of the present research was to look into the question of whether teachers are accurate judges of their students' creativity. Do they see it? Or are their judgments clouded by concerns about classroom behavior management and control? This line of research is important to determine ways to help teachers recognize a broader range of creative students.

\section{CREATIVITY IN SCHOOL}

As the above example illustrates, there are several reasons why creativity may be especially difficult to appreciate and encourage in a classroom setting: First, impediments to creativity are incorporated into the educational system in the form of regulations and control functions that teachers need to uphold [4]. In an ordinary classroom environment, it is not always easy for a teacher to encourage creative behavior and at the same time keep control of her or his students. For example, most teachers would not dare to risk bedlam and allow 25 children to paint their faces green. Second, some well-documented constraints on creativity are part of day-to-day life in school, such as 
competition, rewards and deadlines [5-7]. Much research has shown that extrinsic motivators, such as those just mentioned, thwart creativity, whereas intrinsic motivation, that is, the enjoyment of doing something for its own sake, is conducive to creativity. The reality is that throughout the school day, students fulfill many tasks in order to please the teacher or to get good grades and not for the fun of doing them. Third, the influence of teachers' attitudes toward creativity has been found to be problematic. Research has indicated that the majority of teachers react negatively to students who exhibit personality traits associated with creativity, such as non-conformism, determinedness and individualism, because they see them as potential management problems [8, 9]. In one study, Westby and Dawson [9] demonstrated that even teachers who asserted that they wanted to encourage their students' creativity tended to report that their favorite student exhibited few, if any, of the kinds of traits that have been linked with creative persons. Importantly, however, the traits exhibited by teachers' least favorite students were often those associated with high levels of creativity.

In addition to forming unconscious biases against creative children, teachers also unwittingly thwart their students' creativity in other ways as well. It has been shown, for example, that teachers generally pose more convergent than divergent questions; that is, they favor questions that have only one correct answer [10]. Cornelius and Casler [10] maintained that teachers' and other adults' attitudes toward creative expression and imagination can greatly influence children's perceptions of themselves. On the one hand, there are studies demonstrating that creative teachers have a positive influence on the achievement levels of creative students [8]. On the other hand, if teachers disapprove of creative behavior, creativity among their students will decrease, and creative children may have difficulties accepting themselves as they are and appreciating their creative gift. Cornelius and Casler [10] also claimed that there is always a risk that peers will reject the creative child because she or he dares to be original.

\section{WHAT ARE CREATIVE PEOPLE LIKE?}

To be considered truly creative, it is not enough to just think in novel ways. Creative individuals must also possess sufficient knowledge, skill and ability to allow them to produce an observable and useful product [1,7]. Furthermore, they need to be able to persist with the pursuit of a creative project, to see it to completion, which demands intrinsic motivation and self-confidence to some degree. Numerous researchers [11-14]) have identified adult creative personality traits by asking artists, scientists and writers to describe themselves. Some of the characteristics that are most frequently mentioned are: Enthusiastic, independent, inventive, risk-taking, self-confident, tolerant of ambiguity and non-conformist, but also impulsive, egoistical, cynical and psychopathic.

Other scholars have used non-professional people to indicate what they considered to be the hallmark characteristics of creative persons. The resulting lists of traits fall under the rubric of implicit theories of creativity [9, 1517]; and researchers have, in fact, found moderate relations between teachers' implicit theories about their students' creativity and those students' scores on divergent thinking tests $[15,16]$. Interestingly, however, differences have been reported between teachers' conceptions of creativity and other people's (e.g. college students) conceptions of creativity. Scott [18], for example, demonstrated that teachers were more likely than college students to rate creative children as more disruptive than average (less creative) children.

However, research is somewhat inconsistent. Teachers might not be all wrong in their assessments of creativity. In any classroom, there are both well-adjusted and less wellbehaved creative children. Dawson [19] found that teachers often do recognize the well-mannered creative children, but fail to recognize the less conforming ones. Children with high levels of verbal creativity also tend to be recognized by their teachers more often than students whose creativity is in the figural domain [20]. Dawson et al. [20] argued that there are different aspects of creative performance and that teachers' concepts of creativity represent only one of many possible views of creativity.

Little research has addressed the question of what makes teachers fail in their judgments of creativity and creativity associated traits. Are not teachers supposed to be good at judging the abilities of children? At least they are trained to do so. Why is it so difficult to assess creativity? Are their judgments confounded with other abilities that they are better at recognizing, such as academic achievement level? A second possibility is that teachers are not mistaken, only that the creativity tests are partially invalid because they fail to capture all kinds of creativity.

Another related issue that has not been investigated thoroughly is whether children's self-ratings and teachers' ratings are associated. Students' self-ratings in school subjects generally agree with their teachers' assessments [21]. Testing whether teachers' assessments of creativity are related to children's self-ratings, would provide more understanding for why teachers fail to recognize creativity, especially if compared with the same students' and teachers' judgments in other subjects.

We conducted the present study to further our understanding of teachers' conceptions of creative students. We hoped to determine which variables were most influential in forming teachers' assessments of their students' creativity. Would teachers fail to recognize high levels of creativity in some of their students? Would highachieving children or children who were better behaved and easier to manage be more likely to be counted as creative? And would other children who were nominated as creative by their teachers show high scores on more objective measures of creativity? In addition, we set out to explore the relation between teachers' ratings of their students and the students' self-ratings on creativity and other variables, such as self-image and skills in various school subjects.

\section{AIMS AND HYPOTHESES OF THE STUDY}

We intended to examine:

1 Relations between teachers' assessments of students' creativity, teachers' ratings of students' creative traits and scores on "objective" creativity tests. 
1a) We believed there would be relation between the teachers' assessments of creativity and the nontypical creativity trait list, but not between the teachers' assessments of creativity and the typical creative trait list. However, we expected to find weak relation between teachers' assessments of creativity and the "objective" creativity tests.

1b) We expected a relation between the typical trait list and the objective creativity tests.

2. Relations between teachers' ratings of students indicating them being easily manageable and highachieving with the teachers' assessments of creativity and relations between these students' characteristics and their results on objective creativity tests.

2a) Students rated high by teachers on variables, such as, achievement level, cooperation ability, psychological well-being and self-confidence would also be rated high on creativity by the same teachers.

2b) We did not expect that students scoring high on "objective" creativity tests would necessarily be rated high on these personality traits (variables in 2a).

3. The relation between teachers' assessment of creativity and students' self-ratings in comparison with the relation between teachers' and students' evaluation of academic competence.

3a) We did not anticipate an association between children's ideas of themselves as being creative (operationalized through the question, "I often have good ideas") as compared to their teachers' ratings on a similar question.

3b) In order to investigate whether judgments of creativity is different from the judgments of other abilities, we compared the relation between teacher ratings and the corresponding children's self -ratings on some school subjects and selfimage descriptions (Math, Swedish, Art, achievement level, cooperation ability, psychological well-being and self-confidence). We expected significant relations between the teacher ratings and the corresponding children's own ratings on these items.

\section{METHOD}

\section{Participants}

We chose to collect data from third and fourth grade as we wanted students who were used to the school situation because research has found a dip in creativity at school start $[3,22]$. There are also reports on a $4^{\text {th }}$ grade slump (in Sweden that would be $5^{\text {th }}$ grade) in creativity [23], meaning that creativity during preadolescence may decrease due to the developmental phase that often include a pressure to conform. The participants were thus 8 third graders and 53 fourth graders (31 girls and 30 boys) recruited from six classrooms at three different Swedish schools. Each of these schools had a somewhat different demographic profile, but the majority of children came from middle class homes. In two of the classrooms, only five students participated. The remainder of the children either did not wish to take part or parental permission was not given. In preliminary analyses, these ten participating children were compared with the children from the remaining four classes, where almost all pupils participated. No significant differences on any of the investigated variables were found and the decision was made to combine their data with the information collected on the larger groups. Seven teachers (2 men and 5 women) assessed the students on the teacher rating scale. In one class, a second teacher made the mathematical ratings and their main teacher the other ratings.

\section{Measures}

Three different tests were administered to capture the children's level of creativity. This use of multiple measures allowed us to see whether individuals' levels of creativity were scored differently as a function of the measurement tool and whether the different tests captured creative individuals with different personality trait profiles.

To measure the students' self-image, an established Swedish questionnaire was used. To capture teachers' assessments of their students' creativity, abilities, selfconfidence and creativity related and creativity non-related personality traits a 16-item questionnaire was put together.

The activity questionnaire (AQ). The Activity Questionnaire [24] is a measure of involvement in creative activities and hobbies. The self-report questionnaire assesses whether children engage in any creative hobbies (e.g., drawing and writing stories), whether they spend a great deal of time fantasizing, whether they remember their dreams and whether they have or have once had imaginary companions. The children also indicate whether they have invented their own games or built their own toys. The maximum score for the questionnaire is 12 . The items on this measure that probe creative activities and hobbies have been shown to be related to the Creative Functioning Test [25], and the entire Activity Questionnaire was related to the Alternate Uses test $(r=.34$, $p=.05$ in Hoff [24]; $r s=.44, p=.01$ in Hoff and Carlsson [2]. Homogeneity testing for the questionnaire as a whole gave a Cronbach Alpha of .64 [2].

The creative functioning test (CFT). The Creative Functioning Test [25] is a measure of cognitive flexibility, operationalized as the ability to shift flexibly between imaginative and rational thought. In the CFT, a picture stimulus depicting a black-and-white still life of a bottle and a bowl is shown in repeated rapid presentations on a computer. Shadings and diffuse contours build up the picture, making it fairly easy to imagine other contents (e.g., a body or a landscape). To begin with, the stimulus is presented for a short time $(0.02 \mathrm{~s}$.$) , and for every other presentation the$ exposure time is prolonged until the participant describes the picture content correctly (the longest possible exposure time is $3.6 \mathrm{~s}$ ). Along the way to perceiving the content objectively, a number of subjective interpretations are often reported. When the participant has perceived the actual content of the picture (i. e. a bottle and a bowl), the procedure is reversed. In the decreasing series, the picture is presented at shorter and shorter exposure times and the session is finished when the stimulus can no longer be discerned. The participants are instructed that pictures will be shown very briefly (but not that they will be repeatedly 
viewing the same picture) and they are asked to describe what they think they see on the screen, even if they are not quite certain.

The scoring of this measure in the present study focused on the decreasing series, where new interpretations or recollections of subjective themes from the increasing series are registered. This dimension captures an ability to shift from rational (objective) thought to more imaginative (subjective) cognition, an ability closely related to creativity [3]. In previous research, individuals have been shown to react differently to this task. When correct recognition has been attained, a low creative person will typically inhibit subjective interpretations during the decreasing series. Highly creative individuals, on the other hand, are often able and willing to abandon rational thought and let the subjective representational world influence their perceptions to a considerable extent. Overall, the scoring involves six levels of creativity defined in the scoring manual [25].

In this investigation, each of the authors scored the CFT protocols independently, and in cases of disagreement, a third judge also made an assessment. According to the manual, the re-test correlation for a group of children was .71 [25]. The CFT has been validated through correlation with other measures, e.g., independent raters' assessments of originality and richness of ideas $(\mathrm{G}=.67)$; creativity of children's drawings rated by professional artists $(\mathrm{G}=.74)$ [25].

The Alternate uses test (AUT). The Alternate Uses Test [26] is a widely used measure of fluency of ideas. Also called the Unusual uses test. In the AUT, the participants make up as many alternative uses as possible for a wellknown object, for example a newspaper or a brick. In this study, the Alternate Uses Test was adapted to function as a test for children and empty milk packages were presented as the target. The participants were asked to write down as many uses as they could think of in 15 minutes. The total number of uses was counted and every suggestion was given one point.

How I think I am. How I Think I Am is a Swedish selfimage inventory for children [21] consisting of five subscales. In this study, three of these scales were used to measure: (a) achievement level - e.g., "I'm doing well in school", "Other people do things better than I do", (b) mental well-being - e.g., "I get angry easily", "I'm a happy person", (c) relationships with peers and others - "I have many friends", "I feel different from others". Within the three subscales, five individual test items were also selected to be used as single variables for comparison with the teacher ratings. More specifically, there was one item related to creativity ("I often have good ideas"), one item scoring mathematics skill ("I'm bad in math"), two scoring Swedish language skill ("I'm good at Swedish", "I'm good at reading and writing"), and one scoring Art skill ("I'm good at drawing and painting").

This inventory is of a Likert type. Each item has four response alternatives ranging from "Agree completely" to "Disagree completely", which are scored +2, to -2 (reverse scoring is employed for questions probing negative traits). The greater the sum, the better the self-image. The maximum score is 144 , and the minimum is -144 .
According to the manual, homogeneity testing for this measure showed a reliability of $.91-.93$, and a test to re-test correlation of .74 [21]. The inventory has also been validated through comparison with an adjective list $(r=.75)$ and a psychologist's assessment $(p=.001, \mathrm{~N}=250)$.

Teacher rating scale. The teacher ratings were made on 16 statements using a five-point scale (see Appendix). For each statement, teachers indicated how well the item described each child from "Very well" to "Not at all". Among these sixteen statements eight involved personality and behavior characteristics found to be highly typical or non-typical of creative persons in research [9, 15-17]. Typical characteristics were: Impulsive/emotional, nonconformist, independent and has a lot of ideas. Nontypical characteristics were: tolerant, responsible, logical, and follows rules and instructions well. These eight traits (referred to as typical/non-typical trait lists) were chosen because we considered them to be relevant traits to describe ten-year-old children. Other traits found in the research about implicit theories of creativity [17] tend to be indicative of highly creative adults but would not typically be used to describe a child.

Apart from these eight questions, we also asked the teachers to indicate whether they considered a child to be "creative" (referred to as the teacher assessments of creativity). These data were collected so that we could directly compare teachers' overall judgments of creativity with the creative traits being assessed. Finally, the teachers also indicated whether a child was a high or low achiever, how well the child cooperated with other children, if the child could be described as psychologically well functioning and how self-confident the child was on the last items of the teacher rating scale. These last questions were comparable with the self-image scales that the children filled out, and were added in order to make possible a comparison between child and teacher ratings. Finally, the teachers also indicated whether the child was good at Mathematics, Swedish and Art.

\section{Procedure}

The test administrator first visited all the classes to introduce herself and to hand out parental permission forms. When parental permission had been given, this same researcher came back a second time to administer two of the creativity tests and the self-image inventory. The CFT was administered individually during the ensuing three weeks.

Parts of the results have been reported in another study [2] which was the first wave of data collection for this study. The second data collection was the teachers' assessments taking place approximately one year after the initial testing session (due to practical reasons) and these have not been reported elsewhere. Teachers were asked to indicate how well they remembered the children as a means to controlling for the time lapse between the testing sessions.

\section{RESULTS}

Most of the scales and questionnaires were considered normally distributed. However, the Creative Functioning Test was not and requires the use of non-parametric tests. 
Through Principal Component Factor Analysis (varimax rotation), we found that the four typical creative traits and the four least typical creative traits should be considered two separate dimensions: one subscale of four typical creative traits (factor correlations were .46-.87) and one subscale of four non-typical traits (factor correlations were $.70-.87$ ). The alpha levels for these two scales were .73 and .85 , respectively.

Table 1. Means and Standard Deviations Obtained by the Participants on the Different Measures

\begin{tabular}{|lcc|}
\hline \multicolumn{1}{|c|}{ Measures } & Means (SD) & Range \\
\hline \hline Creativity Measures & & \\
Activity Questionnaire & $5.2(2.7)$ & $0-11$ \\
Creative Functioning Test & $3.2(1.9)$ & $1-6$ \\
The Alternate Uses Test & $4.4(3.2)$ & \\
Self-image: How I Think I Am & $75.6(31.9)$ & \\
Achievement level & $12.6(9.7)$ & \\
Psychological Well-being & $13.1(9.6)$ & \\
Relationship to others & $14.8(7.6)$ & \\
Swedish & $3.4(1.3)$ & \\
Teacher Rating Scale & \\
Typical trait list (4-items) & $13.5(3.6)$ \\
Non-typical trait list (4-items) & $9.1(3.9)$ \\
Creativity & $3.5(1.1)$ \\
Achievement level & $3.7(1.2)$ \\
Psychological well-being & $3.7(1.1)$ \\
Cooperation ability & $2.5(1.2)$ \\
Self-confidence & $3.5(1.2)$ \\
Mathematics & $3.7(1.3)$ \\
Art & $3.2(1.0)$ \\
\hline
\end{tabular}

Aim 1: Relations between teachers' assessments of students' creativity, teachers' ratings of students' creative traits and scores on "objective" creativity tests.

Descriptives for the different measures are found in Table 1. Table 2 summarizes the links between the different measures. The teacher assessments of students' creativity (a five-point rating on the adjective 'creative') were highly correlated with both the typical creative trait list $\left(r_{s}=.78, p=\right.$
$.001)$ and non-typical trait list $\left(r_{s}=.45, p<.001\right)$, meaning that, unlike "lay people", teachers believed that responsibility, logical ability, a willingness to follow instructions and tolerance were creative traits, as were impulsivity, having a lot of ideas, independence, and nonconformity (a belief shared by "lay people").

Moreover, teachers' assessment of a student's creativity was related to scores earned on one of three objective creativity tests, The Activity Questionnaire $(r=.32, p=.01)$.

Analyses revealed, however, only one significant relation between the teacher ratings on the typical and non-typical trait lists and their scores on the "objective" creativity tests. Scores on the Activity Questionnaire positively related to the typical trait list $(r=.42, p=.001)$.

Aim 2. Relations between teachers' ratings of students indicating them being easily manageable and high-achieving with the teachers' assessments of creativity and relations between these students' characteristics and their results on objective creativity tests.

In an effort to probe further into the reasons why a teacher would rate a student as creative, we examined a variety of variables. The students (using median split) rated by teachers as high on achievement level $(t=-3.2, p=.01)$, cooperation ability $(t=-2.8, p=.01)$, psychological well-being $(t=-2.5, p$ $=.02)$, and self-confidence $(t=-2.8, p=.01)$, were also rated as significantly more creative by teachers. Importantly, however, there was little relation between teacher ratings on these dimensions and the "objective" creativity tests scores, that is, students showing higher achievement level, more cooperation, psychological well-functioning and selfconfidence did not demonstrate greater creative potential on the creativity measures. Exceptions were scores on the Activity Questionnaire compared between the high and low psychological well-being groups $(t=-2.2, p=.05)$ and selfconfidence groups $(t=-2.6, p=.01)$. Students rated as more mentally healthy and more self-confident scored higher on the AQ. A tendency in the opposite direction was noted for achievement level on the CFT $(U=322, p=.06)$. In this case, those children who were rated by their teacher as low achievers tended to score higher on the CFT.

Fig. (1) illustrates the relation between achievement level (using median split) and teacher assessment of creativity on the one hand and achievement level and the creativity tests on the other hand. More than seventy percent of the students with a high achievement level were also judged by the

Table 2. Relations Between Creativity Measures

\begin{tabular}{|c|c|c|c|c|c|}
\hline Pearson/Spearman rho & AUT & CFT & Typical & Non-Typical & Teacher Assessment \\
\hline \multicolumn{6}{|l|}{ Test of Creative Potential } \\
\hline Activity Questionnaire & $.25^{*}$ & .12 & $.42 * *$ & .00 & $.32 *$ \\
\hline Alternate Uses Test (AUT) & & .18 & -.18 & -.10 & -.14 \\
\hline Creative Functioning Test, CFT (Spearman rho) & & & -.15 & -.14 & -.11 \\
\hline \multicolumn{6}{|l|}{ Teacher Rating Scale } \\
\hline Typical trait list & & & & .24 & $.78^{* *}$ \\
\hline Non-typical trait list. & & & & & $.44^{* *}$ \\
\hline
\end{tabular}


teachers to be creative, whereas only little more than fifty percent of the high achievers earned high creativity scores on two of the tests (AQ and AUT). On the CFT only about forty percent of the high achievers earned high creativity results.

Aim 3. The relation between teachers' assessment of creativity and students' self-ratings in comparison with the relation between teachers' and students' evaluation of academic competence.

We also compared the item closest to the concept of creativity in the children's self-image inventory "I often have good ideas", with a similar item from the teacher ratings ("has a lot of ideas"). There was no relation between scores for these two variables $(r=.11)$, nor was any relation found between the children's self-scoring (I often have good ideas) and the teacher assessed creativity $(r=.22)$ - made on a fivepoint-scale on the adjective "creative". Children's selfscoring was significantly related to scores for the Activity

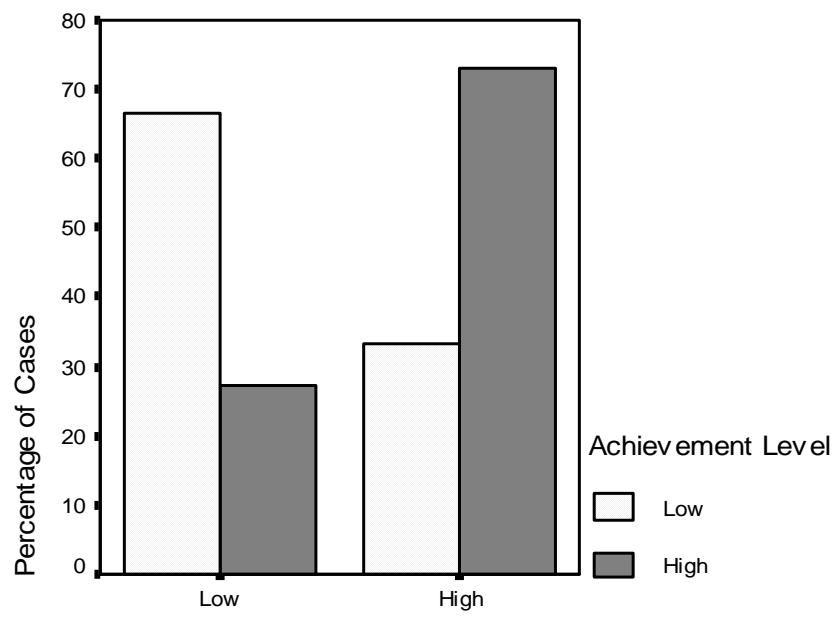

Teacher Assessed Creativity

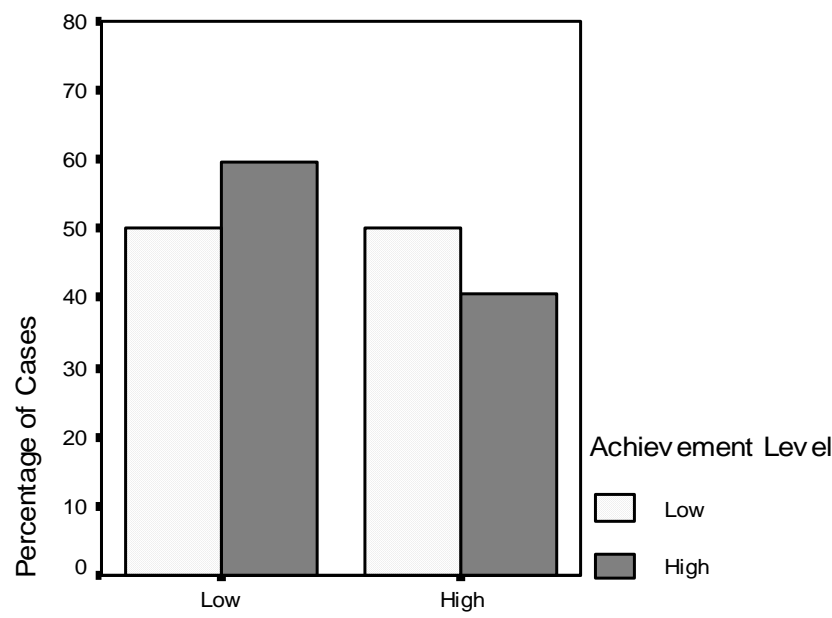

Creative Functioning Test
Questionnaire $(r=.36, p=.01)$ but not to scores for the other two creativity tests.

In contrast to the creativity results, seven of eight relations between students' self-ratings and teacher ratings in different school subjects were significant (Table 3). So too were the relations between children's self-image ratings and teacher ratings on similar traits (also presented in Table 3).

\section{DISCUSSION}

In line with earlier research $[9,18]$, the results of the present study indicate that teachers do not always appear to be accurate in their ratings of children's creativity. Not only did the teachers seem to differ from other lay persons (as derived from earlier research) in their conceptions of creative personality traits, but their creativity assessments were only related to scores for one of the three objective creativity tests that were administered. Earlier research has found moderate relations between teacher

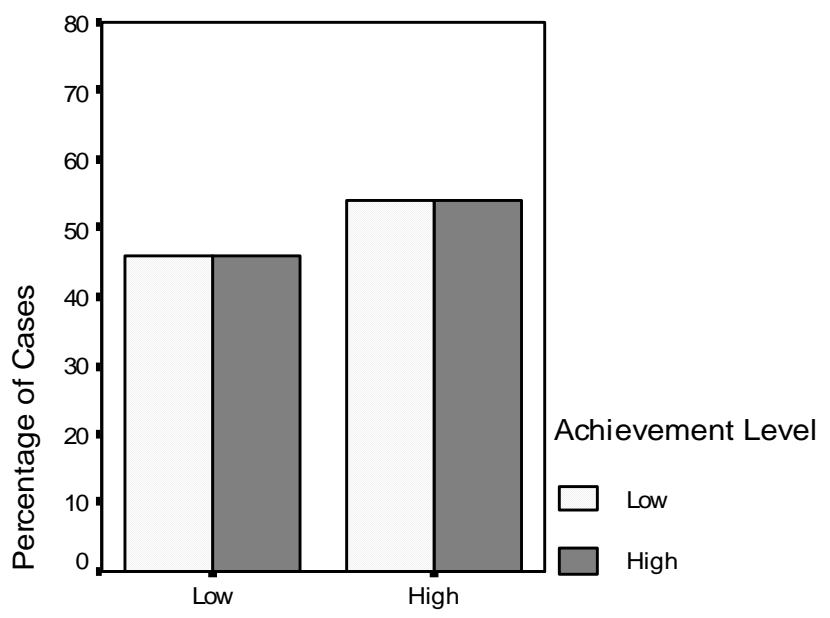

Activity Questionnaire

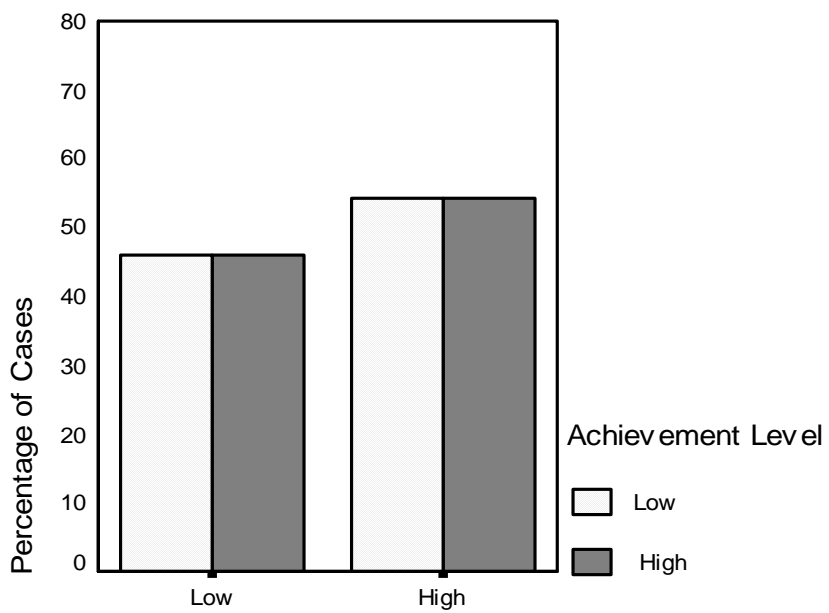

Alternate Uses Test

Fig. (1). Students' achievement level related to teacher assessed creativity and the creativity measures. Note. Median split was used for all measurements 
Table 3. Relations Between Student and Teacher Ratings on School Subjects and Personality Traits

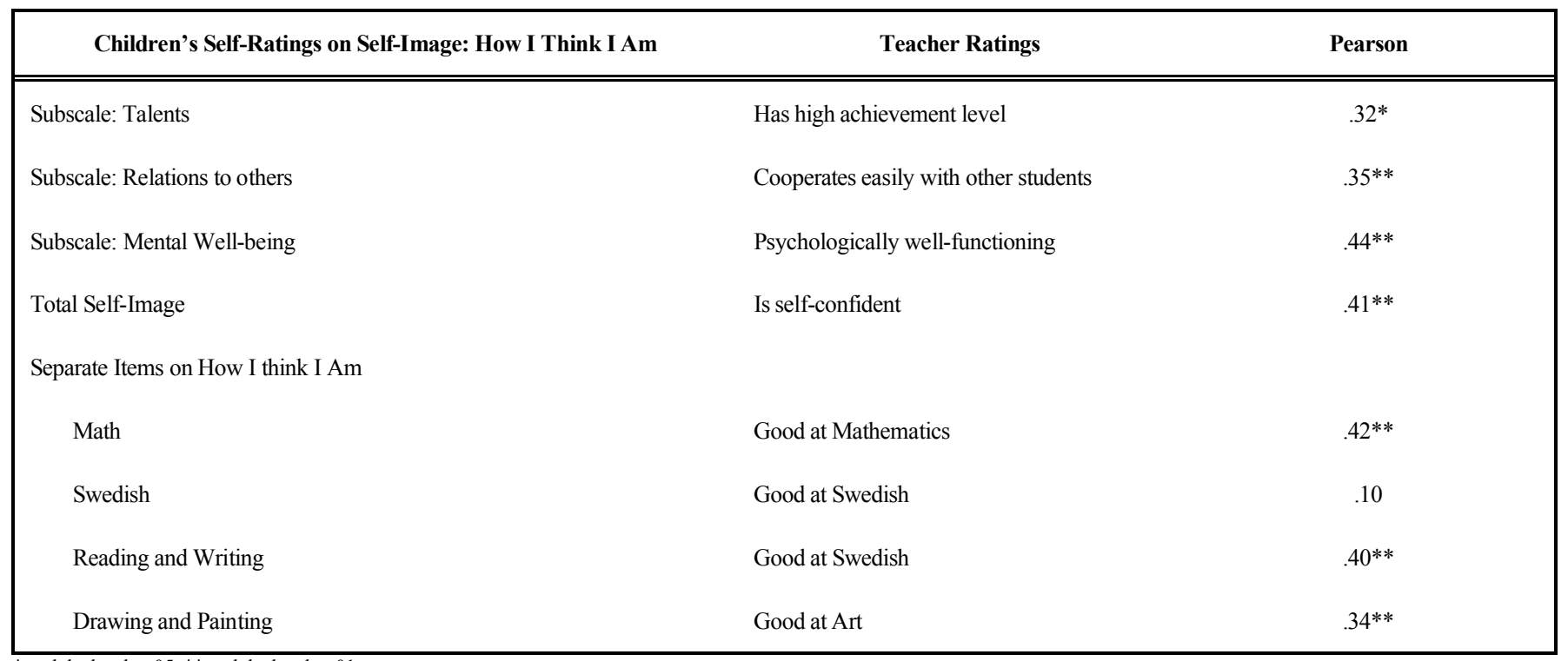

assessments and scores for the Alternate Uses Test [15, 16], but in this study no such relationship was found. Did the teachers in this study then fail to recognize some of the most creative students? Teachers gave a third of the high scorers of the CFT and the AUT the lowest creativity nomination (1 or 2 out of five). About half the high scorers of the objective tests were given the highest creativity nominations (4 or 5). The remaining children were given grades in the middle.

The teacher assessments of their students' creativity were significantly related to the ratings they gave students for typical creative traits (emotional/impulsive, has a lot of ideas, independent, non-conformist) as well as non-typical traits. Interestingly, teachers believed that responsibility, logic, a willingness to follow instructions and tolerance towards others also were traits associated with creativity in children, whereas implicit theories of college students and other laypersons [17,9] placed the latter group of traits among those least typical of creative people.

When analyzing the teacher rated students' traits, we found that the teachers seemed to confound achievement level, cooperation ability, psychological well-being and selfconfidence with creativity. Students with high scores on these self-image variables were assigned significantly higher creativity scores by teachers. The relations between these selfimage variables and scores for the three creativity tests were considerably weaker. There were, however, more psychologically healthy children and self-confident children who scored high on the Activity Questionnaire and more low achievers who scored high on the CFT. In sum, teachers' assessments of their students' creativity appear to be influenced by both a child's perceived achievement level, how able that child is to cooperate in class, the child's psychological wellbeing and her or his self-confidence.

One might argue that these teachers were simply not good at judging the traits and abilities of their students. Yet assessing students is one of the things teachers are supposed to do best and the data did show associations between other assessment dimensions. Children's self-ratings and teachers' ratings of school subjects and self-traits, such as achievement capacity, psychological well-being and self-confidence showed agreement. This indicated that teachers indeed are good judges of children's abilities in general. It was merely on the creativity variable that the link between students' self-ratings and teachers' assessments was vague, that is there was little relation between students' description of themselves as often having good ideas and teachers' assessments on a similar question, which was another indication of teachers' failure to recognize qualities that are related to creativity.

The study indicates that teachers lack adequate knowledge of how to judge and cultivate creativity. Swedish curriculum states that "school should stimulate students' creativity, curiosity and self-confidence and encourage efforts to try new ideas and solve problems." [27; p. 6]. Perhaps teacher training colleges do not prepare teachers for this task appropriately. If teachers are not adequately equipped in their mission, they might run a risk of stifling creativity [28].

To make the picture somewhat more confusing it was not only teachers' assessments that did not match the children's self-ratings. Admittedly, scores for only one of the three objective creativity tests were related to the children's selfratings as well. Not even these tried and true published measures were able to tap children's self-perceptions that they had a lot of good ideas. The question remains whether these children were simply not good judges of their own abilities or whether it is the creativity tests that are not capturing this particular aspect of creativity.

Why is it so difficult to assess creativity? This is a question related to the issue discussed in the introduction about how to define creativity. How do you measure whether something is original and appropriate? How do you measure a generative, productive novel way of perceiving reality? Even if there exists a lot of creativity tests, there is not one measurement that 
without a doubt can be said to tap creativity per se. However, different creativity tests or assessments generally do show some agreement. Hoff and Carlsson [2] demonstrated that the three creativity tests used in this study were significantly associated. Why were the teachers and the creativity measurements so mismatched? We can think of several reasons for why teachers' assessments of creativity might be biased due to their assumed preference for easily managed classrooms. First, keeping a classroom quiet and tidy might not be possible with children displaying characteristics, such as impulsiveness, emotionality, non-conformism, independence and perpetual idea generation. Typically teachers rather want their students to have what other people have nominated as non-typical creative traits (e.g. tolerance, responsibility, logical ability and a willingness to follow rules and instructions), because those traits make the students more manageable in a classroom. This was what Westby \& Dawson [9] demonstrated. However the Swedish teachers of the present study did nominate both the typical and the non-typical traits as creative, a fact that makes this argument less tenable. Second, one reason for the disagreement found in the present study between teachers' ratings and children's selfratings as regards being an idea generating person or not, might be that the teachers did not think or were not aware of a student's idea generation taking place outside school, nor idea generation in situations where the creative ideas perhaps caused management problems in the classroom, such as pranks (depending on who is the judge, even a prank can be novel and appropriate (!) at times). The teachers probably only counted the kind of idea generation that was linked to school work. Finally, as has been brought up earlier, the teachers' ratings on achievement level, cooperation ability, psychological well-being and self-confidence appeared to be strongly related to their concept of creativity. They seemed to have difficulties in distinguishing between for instance a student's academic achievement level and her or his creativity. More than seventy percent of the students with a high achievement level were also judged by the teachers to be creative.

\section{Different Aspects of Creativity and Creative Personality Types}

Thus, little meaningful association was found between teacher's ratings of creativity and other measures, but this was also the case between the implicit trait measures and the objective tests. How can this confusing result be explained? Dawson and associates [20] assessed student creativity in producing verbal and figural real-life products and compared scores earned on these measures with scores for a checklist of typical creative traits (according to traditional views) and teacher-defined creative traits. They found that teachers' conceptions of creative traits were linked to verbal creativity, while the traditional concepts of creativity were tied to figural creativity. In the present study, scores for the indirect measures of student creativity, that is the divergent thinking test (AUT) and the perceptual test (CFT), were neither linked to typical creativity traits nor to the teachers' assessments of creativity. However, student responses on the self-report questionnaire about creative activities (AQ) were associated with scores they received on the typical trait checklist and with the teacher assessment of creativity. The inference to be drawn here is that there may be more than one creative personality type -- and perhaps no one test has yet been devised which can capture the full range of creative individuals. On the one hand, there is the nonconformist rebel with traits corresponding to the traditional concept tapped in so called implicit theories of creativity $[15,16]$ as well as many objective creativity tests that primarily tap figural abilities. The child who paints his face green in art class and who is often considered by teachers to pose a management problem would fall into this category. On the other hand, there is the high-achieving creative student who is not perceived as a threat or a nuisance [20]. This is the kind of student whose creative talents are recognized and appreciated by teachers and validated by high scores on selfreport measures like the Activity Questionnaire and many verbally-based creativity tests. Then there might be even other creative personality types, such as those tapped by AUT and CFT. In another study, Hoff and Carlsson [2] demonstrated that there was no specific self-image profile associated with highly creative ten-year-old children as assessed by the AUT and the CFT (none of the subscales of How I Think I Am were linked to these creativity measures). But in a cluster analysis three different profiles for particularly creative children were found. In the present study, there emerged a marginally significant difference between CFT scores earned by students with high and low achievement level, to the advantage of low achievers. Taken together, these findings suggest that the low achieving, perhaps illogical student might be a third creative type whose potential is less likely to be recognized or appreciated by teachers.

\section{Limitations and Suggestions for Future Approaches}

One methodological criticism of this study might be that we did not construct an implicit theory based on a Swedish sample of laypersons. Instead, we relied on the implicit assumptions of Americans and attempted to compare their naïve notions of creativity to a sample of Swedish children. To be realistic, the differences in perceptions of persons from the US and Sweden would not be expected to be that great. And, in fact, we decided to omit this first step after having seen the results of a master paper [29] at our university showing that implicit theories in the US and Sweden do not differ substantially.

Furthermore, similar studies as the present needs to be performed with a larger sample of children in order to indicate whether the results are generalizable on a larger population. More research on classroom creativity would further the knowledge about the relations between different creativity assessments, explicit as well as implicit, personality traits, and creativity as teachers recognize it. Future approaches would do well to employ a combination of adjective check lists assessing creativity and a variety of self-traits (filled out by students, their teacher and possibly parents as well), verbal and figural objective tests of creativity and real-world (product-based) creativity assessments [1, 22]. Such knowledge is needed in order to learn more about what aspects of creativity different tests actually capture.

The indication of this study that teachers do not have appropriate knowledge of what creativity is and how to judge it is an area of research that needs to be investigated further. 


\section{CONCLUSIONS}

The results showed that teachers' concepts of creativity seem to differ from other groups' implicit theories (as derived from earlier research). Students rated as creative by teachers were characterized by typical creative traits (Impulsive/emotional, nonconformist, independent and has a lot of ideas) as well as non-typical creative traits (tolerant, responsible, logical, and follows rules and instructions well). Furthermore, students rated high on variables such as achievement level, cooperation ability, psychological wellbeing and self-confidence were also rated high on creativity by teachers. There was little relation between these variables and the scores earned on objective creativity tests. The outcomes of these creativity tests were neither linked to the typical nor the non-typical trait list, with one exception: Scores earned on the Activity Questionnaire were linked to assessments on the typical trait list. A comparison between teacher ratings of their students' creativity and students' selfassessments also demonstrated little association. However, the results did show that teachers' ratings and their students' self-ratings were significantly related on other dimensions, such as school grades and self-image descriptions.

The lack of knowledge concerning what creativity is and what kind of characteristics that can be expected of a creative person that was demonstrated among teachers in this study is worrying. Have teacher training colleges failed to cover this important task? The Swedish curriculum states that school should develop students' creativity. How can teachers further students' creativity if they are not given the right equipment? Further studies are warranted to explore whether teachers know how to stimulate creativity.

\section{ACKNOWLEDGEMENTS}

We would like to express our gratitude to the participating children and their teachers. We would also like to thank Ulrika Nordin and Pia Lotta Billing who collected part of the data base and Gudmund Smith who co-assessed part of the CFT-protocols. Thank you Beth Hennessey and Malcolm Watson for reading the paper and giving many useful pieces of advice.

\section{CONFLICT OF INTEREST}

None declared.

\section{APPENDIX}

\section{Teacher Rating Scale}

The students name:

\begin{tabular}{|lccccc|}
\hline & \multicolumn{3}{c|}{ Describe Student } \\
& Poorly & & Well \\
\hline \hline Responsible & 1 & 2 & 3 & 4 & 5 \\
Impulsive/emotional & 1 & 2 & 3 & 4 & 5 \\
Logical & 1 & 2 & 3 & 4 & 5 \\
Has a lot of ideas & 1 & 2 & 3 & 4 & 5 \\
Independent & 1 & 2 & 3 & 4 & 5 \\
Creative & 1 & 2 & 3 & 4 & 5 \\
Follows rules and instructions well & 1 & 2 & 3 & 4 & 5 \\
Psychologically well & 1 & 2 & 3 & 4 & 5 \\
\hline
\end{tabular}

\begin{tabular}{|llllll|}
\hline Cooperates easily with other students & 1 & 2 & 3 & 4 & 5 \\
Self-confident & 1 & 2 & 3 & 4 & 5 \\
Conforming & 1 & 2 & 3 & 4 & 5 \\
Tolerant toward others & 1 & 2 & 3 & 4 & 5 \\
High achievement capability & 1 & 2 & 3 & 4 & 5 \\
Good at Maths & 1 & 2 & 3 & 4 & 5 \\
Good at Swedish & 1 & 2 & 3 & 4 & 5 \\
Good at Art & 1 & 2 & 3 & 4 & 5 \\
\hline
\end{tabular}

\section{REFERENCES}

[1] Amabile TM. Social psychology of creativity: A consensual assessment technique. J Pers Soc Psychol 1982; 43: 997-1013.

[2] Hoff EV, Carlsson I. Shining lights or lone wolves? Creativity and self-image in primary school children. J Creat Behav 2002; 36: 1740.

[3] Smith GJW, Carlsson IM. The creative process: A functional model based on empirical studies from early childhood to middle age. Madison: International Universities Press 1990.

[4] Gardner H. Unschooled minds - How children think and how schools should teach. New York: Basic Books 1991.

[5] Amabile TM, DeJong W, Lepper, MR. Effects of externally imposed deadlines of subsequent intrinsic motivation. J Pers Soc Psychol 1976; 34: 92-8.

[6] Amabile TM, Goldfarb P, Brackfield SC. Social influences on creativity: Evaluation, coaction, and surveillance. Creat Res J 1990; 3: 6-21.

[7] Hennessey BE. The social psychology of creativity. Scandinavian J Educ Psychol 2003; 47: 253-71.

[8] Torrance EP. Rewarding creative behavior. Englewood Cliffs, NJ: Prentice-Hall, Inc 1965.

[9] Westby, E. L., Dawson, V. L. Creativity: Asset or burden in the classroom. Creat Res J 1995; 8: 1-10.

[10] Cornelius G, Casler J. Enhancing creativity in young children. Strategies for teachers. Early Child Develop Care 1991; 72: 99106.

[11] Barron F, Harrington DM. Creativity, intelligence and personality. Ann Rev Psychol 1981; 32: 439-76.

[12] Csikszentmihalyi M. Creativity: Flow and the psychology of discovery and invention. New York: Harper Perennial 1996.

[13] Eysenck HJ. Creativity and personality. In: Runco M, Ed. The creativity research handbook volume one. Cresskill (NJ): Hampton Press 1995; pp. 41-66.

[14] Sternberg RJ, Lubart TI. The concept of creativity: Prospects and paradigm. In: Sternberg RJ, Ed. Handbook of creativity. Cambridge, MA: Cambridge University Press 1999; pp 3-16.

[15] Runco MA. Teachers' judgments of creativity and social validation of divergent thinking tests. Percept Mot Skills 1984; 59: 711-7.

[16] Runco MA. Creativity theories and themes: Research, development, and practice. Burlington, MA: Elsevier Academic Press 2007.

[17] Sternberg RJ. Implicit theories of intelligence, creativity, and wisdom. J Pers Soc Psychol 1985; 49: 607-27.

[18] Scott CL. Teachers' biases toward creative children. Creat Res J 1999; 12: 321-8.

[19] Dawson VL. In search of the wild bohemian: Challenges in the identification of the creatively gifted. Roeper Rev 1997; 19 (3): 148-52.

[20] Dawson VL, D'Andrea T, Affinito R, et al. Predicting creative behavior: A reexamination of the divergence between traditional and teacher-defined concepts of creativity. Creativity Res J 1999; 12: 57-66.

[21] Ouvinen-Birgerstam P. Jag tycker jag är [How I think I am]. Stockholm: Psykologiförlaget. (Original work published 1985) 1999.

[22] Urban KK. On the development of creativity in children. Creat Res J 1991; 4: 177-91.

[23] Torrance EP. A longitudinal examination of the $4^{\text {th }}$ grade slump in creativity. Gifted Child Quart 1968; 12: 195-7.

[24] Hoff E. En målares gåta: En berättelse som utgångspunkt för att studera kreativitet hos 10-åringar [A painter's mystery: A story as a 
starting-point to study creativity in 10-year-old children]. Nord Psykol 2000; 52: 37-77.

[25] Smith GJW, Carlsson IM. CFT: Creative functioning test. Lund: Department of psychology. (Original work published 1990) 2001.

[26] Guilford JP. The nature of human intelligence. New York: McGraw-Hill Book Company 1967.

[27] Lgr11. Läroplan för grundskolan, förskoleklassen och fritidshemmet [Curriculum for elementary school, preschool and after-school program]. Stockholm: Skolverket 2011.
[28] Nickerson RS. How to discourage creative thinking in the classroom. In: Beghetto RA, Kaufmann JC Eds. Nurturing creativity in the classroom. New York: Cambridge University Press 2010; pp 1-5.

[29] Ostlund M. Swedish high school students' implicit theories of creativity - a comparison of the explicit versus the implicit approach in assessing creativity. Unpublished Master's Thesis. Lund University, Lund, Sweden 1996.

Received: May 15, 2011

Revised: June 23, 2011

Accepted: July 25, 2011

(c) Hoff and Carlsson; Licensee Bentham Open.

This is an open access article licensed under the terms of the Creative Commons Attribution Non-Commercial License (http://creativecommons.org/licenses/by-nc/

3.0/) which permits unrestricted, non-commercial use, distribution and reproduction in any medium, provided the work is properly cited. 